\title{
Delimitando a fronteira para a identificação de competências para a capacitação de professores de engenharia para o ensino a distância
}

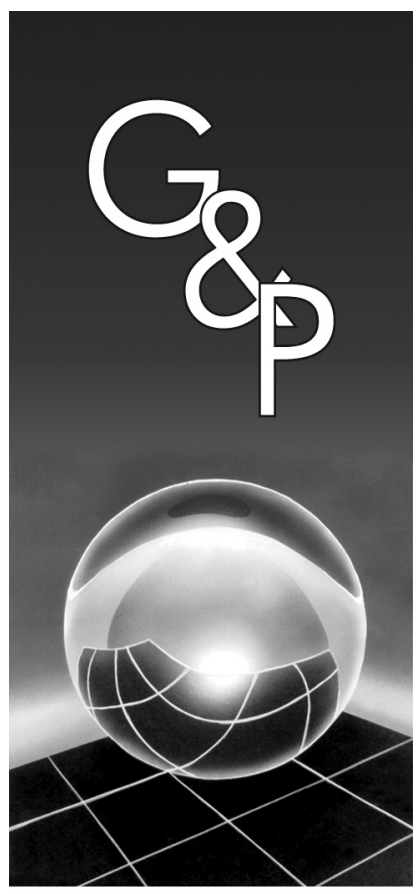

Wesley Peron Seno

Renato Vairo Belhot

\begin{abstract}
Resumo
A educação vive um tempo revolucionário em que as esperanças se contrastam com as incertezas, tornando os resultados imprevisíveis. As concepções de tempo, espaço, real, material e virtual passam por um processo de resignificação em busca de novas formas de se ensinar. Nos últimos anos, a educação a distância (EaD) vem se destacando como uma alternativa educacional possibilitando uma maior flexibilidade no processo de ensino e aprendizagem e sendo útil principalmente como suporte em praticamente todas as áreas do conhecimento, dentre as quais estão as Engenharias. Embora a educação a distância possa ser implementada por meio de diversas metodologias e tecnologias, é importante enfatizar que ela não deve ser aplicada nos mesmos moldes do modelo tradicional de ensino. Na tentativa de prevenir que isso ocorra, enfatizou-se a importância da capacitação docente a partir da premissa de que o professor é um dos elementos principais no processo de ensino e aprendizagem a distância. Assim, este artigo apresenta a concepção de uma matriz de relacionamentos que auxilia na identificação de competências que são desejáveis para os professores de engenharia atuarem na EaD. Nesse sentido é realizada uma ilustração da matriz no contexto da engenharia de produção. Essa matriz delimita a área de fronteira, da qual as competências podem ser extraídas, facilitando, assim, sua identificação. A concepção da matriz de relacionamentos se baseou na correlação de algumas teorias de ensino e em processos de capacitação docente.
\end{abstract}

Palavras-chave: Educação a distância. Capacitação docente. Engenharia. Competências. Matriz de relacionamentos.

\section{Introdução}

Há cerca de 350 anos, os livros, os manuais e os textos didáticos foram introduzidos no processo de ensino. Isso permitiu a relação de um só professor com numerosos alunos, tornando possível aumentar a produtividade da educação, reduzir seus custos e massificá-la, terminando assim com uma fase de ensino personalizado, abandonando a ideia de que cada processo de aprendizagem é único. Hoje, as novas tecnologias, aliadas aos novos paradigmas de ensino, podem voltar a personalizar o processo de aprendizagem, sem renunciar ao número de alunos por professor e até ampliá-lo. Essas tecnologias permitem que os estudantes selecionem e produzam seus próprios itinerários educativos, dosem a complexidade dos conteúdos segundo seu próprio ritmo e rompam com a atual rigidez de tempo e espaço (TEDESCO, 2004). Os novos modelos educacionais com seus processos de mediações procuram atender a espaços e tempos diferentes, submetidos também a contextos diferentes, como é o caso da educação a distância (EaD) que surgiu não como solução para todos os problemas, mas para cumprir um papel relevante como modalidade de educação do futuro. De acordo com o Decreto n. ${ }^{0} 5.622$, de 19 de Dezembro de 2005, a EaD se caracteriza como modalidade educacional na qual a mediação didático-pedagógica nos processos de ensino e aprendizagem ocorre com a utilização de meios e tecnologias de informação e comunicação, com estudantes e professores desenvolvendo atividades educativas em lugares ou tempos diversos.

Segundo Oliveira (2003), a queda de barreiras de espaço e tempo é, simultaneamente, o principal desafio e trunfo para a expansão da $\mathrm{EaD}$, que não se configura apenas como uma modalidade, um modo, um meio, um sistema, uma estratégia de oferta e acesso, mas sim como uma possibilidade de resignificar a educação no movimento 
que pode ser mais bem identificado como transição na ruptura com o paradigma tradicional.

Em relação ao ensino de engenharia, mais especificamente, este ainda está muito pautado no modelo tradicional, que é baseado essencialmente na transmissão e recepção da informação, ignorando as individualidades, preferências e conhecimentos prévios dos estudantes (BELHOT, 2005a). Entretanto, é de se esperar que a aplicação única desse modelo tenha dificuldade de sobrevivência, face à velocidade de modificação e surgimento de novas informações e tecnologias. Tal afirmação é válida para o ensino presencial na sua modalidade formal e muito mais intensamente para o ensino virtual na modalidade a distância, em que há um incremento significativo de escala. Não há como garantir que esse modelo formal forneça bases sólidas para novas modalidades de ensino. Desse modo algumas transformações são esperadas no campo do ensino de engenharia. Assim como a produção em massa caminha para a produção enxuta, ágil e flexível, a educação em engenharia também caminha para um novo modelo, que pode encontrar no ensino a distância um aliado para eliminar duas das barreiras que caracterizam o modelo de ensino formal, especificamente, tempo e espaço. Essas transformações devem afetar professores e alunos.

Silva e Cecílio (2007) salientam que o ensino nas engenharias ainda está distante de um modelo adequado. Para que haja uma melhoria é necessária uma mudança no modelo de ensino tradicional.

Para Belhot (1997), os cursos de engenharia preferem enfocar problemas muito estruturados e de caráter operacional. São problemas que normalmente aceitam uma única solução ótima e que acabam por reforçar a aplicação de uma sequência de passos para a obtenção da solução, quando o conceito de solução em engenharia, normalmente aponta para uma gama de alternativas tecnológicas e não para uma única verdade.

Atualmente, a ênfase dada à capacitação do professor está mais alicerçada no aspecto tecnológico, ou seja, capacitar o professor para utilizar tecnologias de ensino a distância. Diante disso, surge uma pergunta: será que somente a ênfase tecnológica é suficiente para atender a educação a distância? Segundo Seno e Belhot (2006a) é preciso estabelecer um processo de capacitação docente baseado em competências que enfatizem aspectos educacionais, de modo que o próprio professor não limite o potencial da $\mathrm{EaD}$ e possa garantir eficiência e qualidade em sua aplicação.

Este artigo apresenta a concepção de uma matriz de relacionamentos originada a partir de um processo de capacitação docente e de quatro bases educacionais teóricas, a saber: a) modelo não formal de ensino; b) objetivos instrucionais; c) estilos de aprendizagem; e d) ciclo de aprendizagem. Essa matriz auxilia na delimitação do escopo para a especificação das competências a serem desenvolvidas por docentes de engenharia quando da utilização da EaD, constituindo-se em um referencial para a elaboração de programas customizados de capacitação docente. Com o intuito de ilustrar essa customização foram criados alguns exemplos e discussões sobre a utilização da matriz de relacionamentos na engenharia de produção. A apresentação das competências identificadas a partir dos quatro referenciais teóricos e a descrição das etapas do processo de capacitação não são foco deste artigo.

Este trabalho está organizado da seguinte maneira: a seção 2 fornece uma visão geral do professor na educação a distância e discute o professor de engenharia dentro desse contexto; a seção 3 descreve os quatro referenciais utilizados como base para a concepção da matriz de relacionamentos, considerando em cada um deles o professor de engenharia; a seção 4 discute a inter-relação entre as bases teóricas e apresenta a matriz de relacionamentos propriamente dita; a seção 5 ilustra e discute a matriz de relacionamentos para a capacitação de docentes nas engenharias de produção; por fim, a seção 6 apresenta algumas considerações.

\section{0 professor na educação a distância e o professor de engenharia}

Diferentemente do modelo tradicional de ensino em que o professor está acostumado a ser o centro das atenções, a educação a distância requer mudanças em seu comportamento. Para se adaptar a essas mudanças, o professor necessita repensar sua maneira de ensinar, de aprender e de pesquisar. Nesse novo cenário, ele precisa organizar, administrar e regular situações de aprendizagem, deixando de ser o "dono do saber" e o controlador da aprendizagem, para tornar-se um mediador que estimula a curiosidade, o debate e a interação com os outros participantes do processo. No lastro de uma transição paradigmática, o professor desafia, orienta e acompanha o percurso e o resultado dos estudos, investigações e elaborações desenvolvidas pelo aluno, individual e coletivamente, passando assim a construir o conhecimento ao invés de reproduzi-lo, juntamente com os alunos. Em relação ao professor de engenharia, esse mesmo pensamento é compartilhado por Matos e Rudolf (2006): "a ação pedagógica do docente de engenharia deve estar orientada para a construção do conhecimento e não para a sua reprodução".

Dentro desse contexto de mudanças no papel desempenhado pelo professor, podem-se distinguir três categorias de professores:

- Professor Conteudista (autor): é o profissional que tem a responsabilidade de construir o material didático de um curso ou disciplina, desenvolvendo-o de acordo com um design instrucional especializado para o paradigma de $\mathrm{EaD}$;

- Professor Responsável: é o profissional responsável pela disciplina ou curso. Ele assina pela execução, 
acompanhamento e avaliação da disciplina, e trabalha em conjunto com seus tutores orientando-os pedagogicamente nas questões relativas ao desenvolvimento dos conteúdos;

- Professor Tutor: seu papel na EaD é de grande importância. Sua maior responsabilidade é a orientação concreta dos estudantes, contribuindo com conhecimento especializado e perspicácia, tecendo com o estudante linhas de discussão e colhendo o feedback das atividades de aprendizagem. Os professores tutores motivam a aprendizagem, esclarecem as dúvidas e resolvem os problemas que surgem durante o estudo. Ele sintoniza as propostas dos conteúdos com a bagagem cultural dos interlocutores, fornecendo orientações e propostas para que o estudante avance em sua aprendizagem. O tutor acompanha e atende o estudante (a distância ou presencialmente) durante o seu percurso de aprendizagem.

Embora essas categorias de professores sejam utilizadas na educação a distância independentemente das áreas de atuação do professor, deve-se ter um cuidado especial com as engenharias. Segundo Reis (2008), no que diz respeito aos professores de engenharia, acentua-se a necessidade de diferenciação entre os objetos de trabalho no campo da engenharia e no campo da docência. Bazzo (1998), citado por Reis (2008), afirma que o professor de engenharia procura ratificar dentro da sala de aula a missão de representar o profissional engenheiro mesmo atuando no sistema de ensino. Isso significa que eles agem tratando o sistema de ensino-aprendizagem da mesma forma como as regras não escritas da profissão.

Hidalga (2006), baseado em seus estudos, diz que os professores de engenharia, no exercício de sua prática, se articulam levando em consideração alguns tipos de saberes: os referentes à experiência, os didático-curriculares, os atitudinais e os críticos-contextuais. Isso mostra que a docência em cursos de engenharia ainda está fortemente influenciada pela epistemologia dominante, própria da ciência moderna.

Outro aspecto interessante observado nas considerações do trabalho de Hidalga é o destaque de algumas características analisadas a partir de experiências inovadoras na formação do professor de engenharia. O curioso é que algumas dessas características se assemelham às da educação a distância, por exemplo: ruptura com a forma tradicional de ensinar e aprender; gestão participativa de professores e também de alunos; reconfiguração de saberes.

Para Belhot (1997), a abordagem do livro de receitas ainda está presente no ensino de engenharia, onde os professores passam o problema e as respectivas ações bem definidas, em sua ordem apropriada, para solucioná-lo. Dessa forma o ensino passa a ser dependente da especialidade do professor e do domínio da técnica. Embora os professores de engenharia valorizem as atividades de planejamento e racionalização de métodos e processos nos seus respectivos campos de trabalho profissional, quando se trata do ensino, parece que não há a mesma atitude.

Por meio de uma contradição, Silva e Cecílio (2007) dizem o seguinte: de um lado estão os engenheiros que se tornam professores e ensinam o que sabem fazer, e de outro estão professores que ensinam o que não fazem na prática. Uns ensinam em decorrência de sua formação e exercício de sua profissão, porém, às vezes, sem o reconhecimento ou a intencionalidade da dimensão pedagógica do trabalho docente. Outros transmitem e ensinam a teoria, muitas vezes sem as conexões com a prática. A dissociação entre teoria e prática dificulta o processo de ensino e aprendizagem. Nesse sentido, professores de engenharia têm uma nova função na sala de aula: ensinar o que sabem e o que fazem, com uma intencionalidade e uma prática pedagógica própria.

É preciso que o professor de engenharia tenha tempo e oportunidades de se familiarizar com suas novas funções (conteudista/autor, responsável e tutor) e com as novas tecnologias educativas, de modo que ele possa fazer escolhas conscientes sobre o uso de formas mais adequadas de ensinar determinados assuntos para grupos específicos de alunos. Segundo Smith e Waller (1997), as maiores mudanças no ensino ocorrem principalmente quando os professores começam a ter a visão de sua importância no processo de adaptação e de mudanças, e quando começam a enxergar seu verdadeiro papel nesse novo paradigma de ensino.

Estruturar um processo de capacitação baseado em competências relacionadas às teorias de ensino pode ser o diferencial entre preparar professores e preparar bons professores para a educação a distância.

\section{Bases de sustentação da matriz de relacionamentos}

Esta seção apresenta os quatro referenciais teóricos, denominados aqui de pilares, que serviram de base para a concepção da matriz de relacionamentos. Procurou-se demonstrar a importância de cada pilar e o relacionamento existente entre eles, bem como enfatizar alguns aspectos a serem considerados quando da especificação das competências de um professor de engenharia.

Um estudo mais aprofundado sobre esses quatro pilares pode ser encontrado em Seno e Belhot (2006b).

\subsection{Pilar 1: modelo não formal}

O primeiro pilar considerado como fundamento para a elaboração das competências que um professor deve possuir para ensinar na modalidade a distância enfoca a construção de sistemas de aprendizagem menos formal apoiados pela tecnologia educacional. Segundo Dib (1974), a tecnologia da educação é considerada como a aplicação sistemática de conhecimentos científicos e tecnológicos à solução de 
problemas educacionais. De acordo com o autor, a principal preocupação de uma abordagem tecnológica da educação é desenvolver estratégias, procedimentos e meios que permitam construir um sistema de aprendizagem eficiente por meio da utilização de conhecimentos científicos.

O que se percebe em relação ao professor de engenharia é que ele está acostumado a ensinar baseado em sua formação, exercício de sua profissão e/ou experiência prática. A parte tecnológica, na maioria das vezes, não é problema para esse profissional, mas as questões relacionadas aos conhecimentos científicos normalmente são. Isso significa que somente parte do que Dib chamou de tecnologia da educação (conhecimentos tecnológicos) é utilizada pelo professor de engenharia. A outra parte (conhecimentos científicos) normalmente não é utilizada para solucionar problemas educacionais. Segundo Stump e Zasnicoff (1999), além dos conhecimentos básicos de engenharia, o professor precisa de informação psicológica, sociológica, pedagógica e metodológica (conhecimentos científicos).

$\mathrm{Na} \mathrm{EaD}$, o professor de engenharia precisa se conscientizar que o ambiente de ensino e aprendizagem a distância é muito diferente daquele em que está habituado, e para lidar com esse novo ambiente é necessário que ele saiba construir sistemas de aprendizagem menos formal apoiados pela tecnologia educacional.

A tecnologia educacional, de um modo geral, procura desenvolver estratégias mais eficientes e mais adequadas ao processo de aprendizagem.

O princípio que rege esse primeiro pilar é o de que um sistema de aprendizagem deve ser flexível e construído pela aplicação sistemática de conhecimentos científicos e tecnológicos visando à solução de problemas relacionados ao ensino. A escolha desse tema, como um dos pilares de sustentação da matriz, foi baseada no fato de que a educação a distância "ainda" não é um modelo formal de ensino, e talvez nem venha a ser.

Levando em consideração os estudos realizados por Dib (1974), foram extraídos alguns aspectos a serem considerados para o estabelecimento das competências para se ensinar a distância:

- Importância de se especificar previamente o conhecimento inicial (pré-requisitos) e final que se espera do estudante, em termos mensuráveis, antes do início do processo de ensino, portanto, antes de se iniciar o sistema de aprendizagem;

- Importância de se estabelecer uma sequência de aprendizagem, antes do processo de ensino, portanto, antes de se iniciar o sistema de aprendizagem;

- Importância de se prever realimentação no sistema de aprendizagem, de modo a poder observar se as respostas dadas pelos estudantes, em determinada etapa do sistema de aprendizagem, condizem com às pré-estabelecidas, provendo assim o controle do sistema e do estudante;
- Importância de fomentar a participação ativa dos estudantes, para que esses deem respostas observáveis durante o processo de aprendizagem, possibilitando avaliação e ajustes no sistema; e

- Importância de se especificar objetivos para auxiliar na elaboração e condução do processo de aprendizagem, além de servir de parâmetro para verificar se foram alcançados.

Segundo Belhot (2005a), insiste-se em manter a educação de engenharia em moldes tradicionais, no ensino centrado no professor, segundo os preceitos do que Dib (1974) chamou de modelo de ensino formal.

Para Contreras (2002), citado por Silva e Cecílio (2007), o modelo de professor de engenharia é regido pela racionalidade técnica, em que a prática profissional consiste na solução instrumental de problemas mediante a aplicação de um conhecimento teórico e técnico, previamente disponível que procede de uma pesquisa científica.

\subsection{Pilar 2: objetivos instrucionais}

Nos estudos referentes aos sistemas de aprendizagem menos formal, baseados em tecnologia educacional, observou-se a importância de se estabelecer objetivos de aprendizagem. O reconhecimento da importância e da dificuldade em se determinar tais objetivos impulsionou a criação de um segundo pilar de sustentação para a criação da matriz de relacionamentos.

Segundo Dib (1967), não há dúvida de que em educação se deve procurar atingir determinados objetivos, o problema é que existem dificuldades na hora de se determinar quais objetivos devem ser alcançados e como medir se foram alcançados. O mesmo problema pode ser apontado na determinação de um sistema adequado de recuperação do aprendizado, que se faz necessário toda a vez que os objetivos pretendidos não são atingidos na primeira tentativa.

Como visto anteriormente, o professor de engenharia tem dificuldades em separar seu modo de atuar como "engenheiro" em relação ao "docente engenheiro". Na maioria das vezes é o profissional engenheiro quem ensina ao invés do docente engenheiro. Na atividade de ensinar a distância, o docente engenheiro, além de construir sistemas de aprendizagem menos formal, deve se preocupar em estabelecer e medir objetivos de aprendizagem. Embora a EaD seja considerada um ensino de massa, declarar objetivos educacionais pode possibilitar o tratamento individualizado do estudante uma vez que é possível verificar, para cada aluno, se o objetivo declarado foi atingido.

A taxonomia desenvolvida por Bloom et al. (1972) é um sistema de classificação educacional, fundamentado em lógica e psicologia, que auxilia na identificação de objetivos de aprendizagem. Para esses autores a especificação dos objetivos, além de servir como ponto de partida para o processo de análise de comportamento, permite avaliar a eficiência do sistema de aprendizagem e o desempenho do 
estudante, possibilitando a correção de possíveis desvios durante a aprendizagem. Não tem sentido especificar atividades a serem desenvolvidas pelo estudante, métodos e recursos a serem empregados se não se souber quais objetivos alcançar. Segundo essa taxonomia, os objetivos são classificados por meio das definições operacionais de seis classes principais (Figura 1).

1. Conhecimento: quando o objetivo é classificado no nível de conhecimento, espera-se que o estudante traga à sua mente, ou seja, recupere em sua memória o material apropriado (ex.: conceito, método, processo, etc.) para responder algo ou resolver um problema.

2. Compreensão: quando o objetivo é classificado no nível de compreensão, espera-se que o estudante possa interpretar e/ou inferir algo a partir de conhecimentos já sedimentados, sem a necessidade de recuperar o material apropriado na mente (isso passa a ser algo automático). É representar o conhecimento de diversas maneiras ou formas (ex.: criar um esquema, diagrama, simbologia, descrever com palavras próprias, etc.).

3. Aplicação: no nível de aplicação, espera-se que o estudante consiga aplicar seus conhecimentos compreendidos em outros domínios. Esse nível requer abstração por parte do estudante.

4. Análise: quando o objetivo é classificado no nível de análise, espera-se que o estudante possa explicar, de uma maneira clara e organizada, como ele aplicou determinados conhecimentos compreendidos (fragmentos) na resolução de problemas ou no encadeamento de ideias utilizadas nessa resolução.

5. Síntese: em termos de síntese, espera-se que o estudante consiga, a partir de análises, construir e representar padrões ou estruturas que antes não haviam sido evidenciadas.

6. Avaliação: ao nível de avaliação, o estudante deve avaliar, julgar ou comparar algo a partir de padrões ou critérios selecionados/evocados, constituídos a partir de sínteses.

Sobre a taxonomia, é importante considerar três pontos:

i a definição dessas categorias foi realizada de modo que os objetivos categorizáveis de uma classe

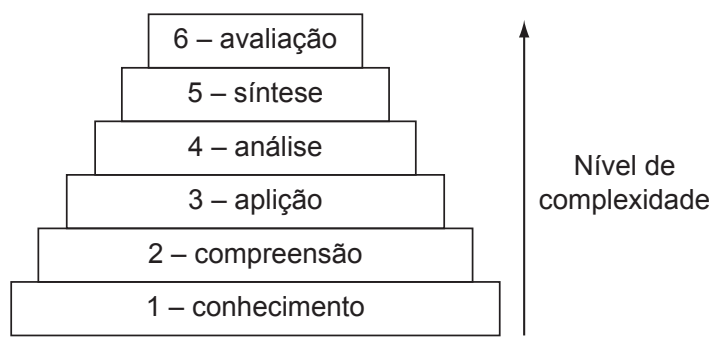

Figura 1. Estrutura da taxonomia - seis classes. compreendessem e se baseassem em comportamentos incluídos nas classes precedentes;

ii essa classificação é indicada para ser empregada onde a especificação dos objetivos é estabelecida em termos de comportamentos pretendidos para o estudante; $\mathrm{e}$

iii quanto mais ampla a definição dos objetivos educacionais mais difícil é fazer uma classificação adequada.

Das informações coletadas sobre esse segundo pilar foram relacionadas algumas observações consideradas importantes e que podem vir a se tornar competências necessárias ao professor quando do estabelecimento de objetivos instrucionais:

- É importante saber em qual nível (classe) da taxonomia de Bloom o estudante se encontra, e qual nível se pretende trabalhar ou se pretende que o estudante atinja;

- É importante saber o quão desenvolvido o estudante está para atingir determinado objetivo;

- É importante saber quais são suas necessidades e interesses;

- É importante saber disponibilizar material didático suficiente para que o estudante consiga atingir o objetivo proposto, dentro do nível da taxonomia trabalhado;

- É importante saber equacionar o tempo necessário para que o estudante atinja o objetivo; e

- É importante saber determinar e avaliar se o comportamento que o estudante apresenta é o esperado.

Com relação à declaração de objetivos educacionais, a taxonomia proposta por Bloom tem dois aspectos que podem facilmente ser incorporados no ensino de engenharia. $\mathrm{O}$ primeiro é o deslocamento do foco do ato educacional para o aluno e o segundo é o estabelecimento de uma associação entre o nível desejado da taxonomia com os objetivos da disciplina e/ou do curso, facilitando a avaliação e tornando a aprendizagem mais significativa.

\subsection{Pilar 3: estilos de aprendizagem}

Com o objetivo de maximizar o processo de aprendizagem dos estudantes foi criado um terceiro pilar que enfatiza a questão dos estilos de aprendizagem como um meio para que os objetivos pretendidos pelos professores sejam alcançados pelos estudantes. Quatro modelos de estilos de aprendizagem têm sido utilizados efetivamente no ensino de engenharia, a saber:

i o modelo de Felder e Silverman (1988);

ii o modelo de Myers, I. B. e Myers, P. B. (1980);

iii o modelo de Keirsey e Bates (1984); e

iv o modelo de Kolb (1984).

Estilos de aprendizagem são construtos, isto é, abstrações que não podem ser observadas ou medidas diretamente, mas 
são úteis para explicar comportamentos (aprendizagem). Significa conhecer as maneiras pelas quais as informações são percebidas e processadas. São as preferências no aprender. Pensando no processo de ensino e aprendizagem, pode-se dizer que é a individualidade no aprender e a coletividade no ensinar. É um processo único e individual.

Os indivíduos possuem diferentes maneiras de perceberem e processarem as informações, alguns estudantes têm sua atenção voltada mais para fatos e dados, enquanto outros gostam mais de teorias e modelos matemáticos. Alguns respondem positivamente às informações visuais, como figuras, diagramas e esquemas; outros preferem as formas verbais - explicações faladas e escritas. Existem ainda os que preferem aprender ativamente com a prática, enquanto outros aprendem de forma individual e introspectiva. Essas diferentes maneiras de ser, compostas por características que representam o perfil dos estudantes com relação à motivação, definem os chamados estilos de aprendizagem. Essas informações são muito importantes, pois ajudam os alunos a se conhecerem melhor e dão suporte ao professor no estabelecimento de estratégias de ensino adequadas, de modo a atingir mais eficientemente os objetivos pretendidos criando um ambiente de aprendizagem que maximize a satisfação do aprender nos estudantes, proporcionando alto grau de motivação (BELHOT, 1997).

Os estudantes aprendem por diversas maneiras e os professores utilizam diversos métodos de ensino para ensinar. Quando há uma falta de sintonia entre os estilos de aprendizagem e os estilos de ensino, resultados desastrosos podem ser obtidos. Esses desencontros geram desempenho ruim dos estudantes, frustração dos professores e uma perda para a sociedade, quando se pensa em formação de futuros profissionais.

Quando a transmissão da informação está alinhada com o modo pelo qual se prefere recebê-la, a hipótese é que haja uma maior eficiência na aprendizagem. A partir disso podem-se citar dois tipos de eficiências no aprendizado. O primeiro é quando a pessoa utiliza seu estilo como uma oportunidade de aprender melhor e o segundo é quando a pessoa adapta seu estilo à forma com que lhe é ensinado.

Como dica para o professor de engenharia, vale destacar que a estruturação de um ambiente de aprendizagem por meio de mixes de formas de apresentação de conteúdos, de estratégias e de métodos de ensino que contemplem os vários estilos, constitui-se em um bom caminho para que os estudantes tenham um melhor aproveitamento das aulas. O desafio está em criar um ambiente amigável para o aprendizado.

Alguns aspectos são considerados importantes para que o professor tenha sucesso em suas atividades:

- Conhecer sobre estilos de aprendizagem, pois ele irá trabalhar com educação a distância que é considerada por muitos como modalidade de ensino em massa na qual o estudante aprende na maior parte do tempo individualmente (pois o contato físico é reduzido) e existe um alto índice de evasão;

- Saber como identificá-los;

- Saber preparar atividades instrucionais e materiais didáticos que mesclem os estilos de aprendizagem, procurando atender à maior parte das preferências de aprendizagem de seus alunos;

- Levar em consideração os estilos de aprendizagem quando da formação de grupos de trabalho; e

- Não utilizar somente os estilos preferenciais de seus estudantes para ensinar, pois eles poderão não desenvolver a destreza mental que necessitam para enriquecer seu potencial.

No ensino tradicional de engenharia utiliza-se muito a apresentação da matéria em aulas expositivas e com apresentação de material pré-concebido, um estilo confortável somente para alguns tipos de estudantes. Segundo Felder (1996), nas últimas décadas o ensino de engenharia foi fortemente direcionado para os aprendizes intuitivos, verbais, dedutivos, reflexivos e sequenciais. No entanto, poucos estudantes de engenharia encaixam-se em todas essas cinco categorias. Eles são na maioria ativos, sensoriais, visuais e globais. Isso significa que a maior parte dos estudantes de engenharia recebe uma educação incompatível com seus estilos de aprendizagem, o que pode prejudicar o desempenho e as atitudes desses em relação às disciplinas, ao currículo e à própria carreira de engenharia. Outra informação interessante é que os professores de engenharia orientam suas disciplinas para os introvertidos, enquanto que seus alunos são na maioria extrovertidos.

\subsection{Pilar 4: ciclo de aprendizagem}

A criação desse quarto pilar se deu em decorrência dos estudos realizados sobre os estilos de aprendizagem, especificamente do modelo de Kolb (1984) que, baseado nos modos de percepção e processamento da informação, determinou quatro tipos de aprendizes, a saber:

I divergentes;

II assimiladores;

III convergentes; e

IV adaptadores.

A partir desse modelo, McCarthy (1986) propõe um sistema de aprendizagem chamado 4MAT que possibilita conceber um ciclo de aprendizagem e ensinar ao redor desse ciclo, contemplando os quatro tipos de aprendizes estabelecidos por Kolb. Segundo McCarthy (1986), citada em Belhot (2005b), a aprendizagem ocorre pela passagem dos quatro quadrantes do ciclo. Assim, a experiência concreta cria uma necessidade para a aprendizagem, que induz a observação reflexiva da experiência, seguida pela indução de conceitos para integrar a nova experiência com o já conhecido. Após a integração, é realizada a avaliação 
e essa ação resulta em novas experiências. É o que se convencionou chamar de "ensinando por meio do ciclo".

Os estilos de aprendizagem de Kolb são caracterizados por McCarthy por meio de perguntas, conforme ilustra a Figura 2.

De acordo com Harb, Durrant e Terry (1993), esse sistema é baseado na suposição de que o aprendizado se desenvolve melhor passando pelos 4 quadrantes do ciclo de aprendizagem que estão associados às 4 perguntas. $\mathrm{O}$ ciclo é um processo estruturado e ordenado em que cada passo ou etapa depende da execução do anterior (Figura 3).

Na etapa "POR QUÊ", representada pela letra P na Figura 3, a temática deve ser apresentada aos estudantes, o contexto e os problemas decorrentes. É uma fase de convencimento, na qual é apresentada uma determinada realidade. Na etapa “O QUÊ" (letra O) são apresentados os conceitos e suportes necessários para modelar e analisar os problemas identificados na etapa anterior.

Na fase "COMO ?" (letra C) os conceitos são aplicados na solução de problemas bem estruturados e que normalmente aceitam soluções ótimas. Na etapa "E SE" (letra E),

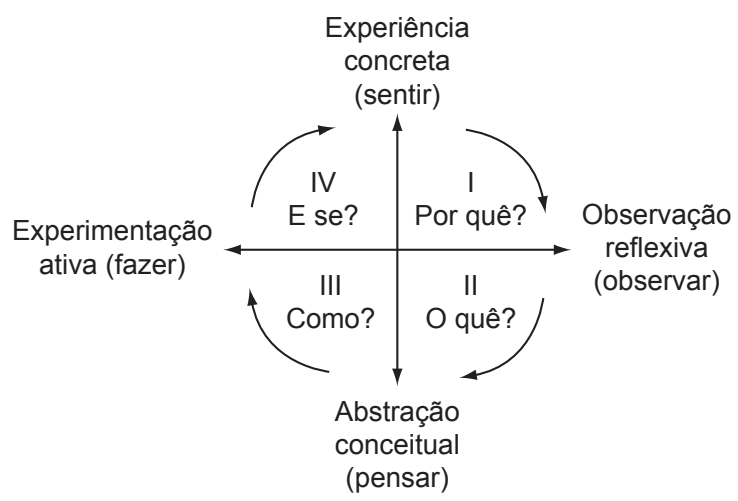

Figura 2. Perguntas incorporadas por McCarthy (1986).
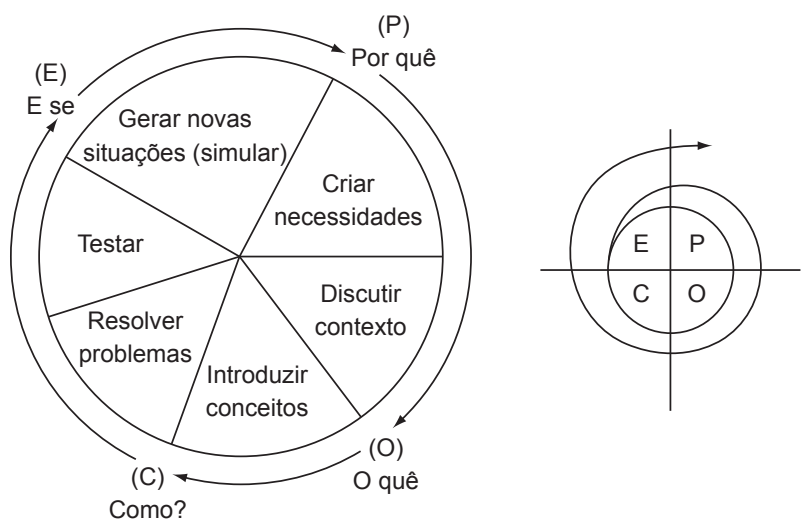

Figura 3. O ciclo de ensino e aprendizagem (adaptado de Belhot, 1997). modifica-se a condição inicial dos parâmetros, criando-se novas situações, novos problemas, sob novas restrições e exigindo novas abordagens de solução.

O professor está acostumado a percorrer o ciclo, mas o estudante não. Isso significa que se o professor está trabalhando, por exemplo, no quadrante II e faz uma pergunta cuja resposta esteja no quadrante IV, o aluno provavelmente não conseguirá responder. Por isso, é importante que o professor saiba colocar suas perguntas no momento certo do processo de ensino, de modo que o estudante seja instigado a responder tendo condições de se tornar um ator ativo no processo de ensino e aprendizagem.

Baseado nos 4 estágios do ciclo de aprendizagem, Stice (1987) diz que experiências concretas formam a base para observação e reflexão e essas, por sua vez, conduzem aos conceitos por meio dos quais novas implicações para as ações podem ser deduzidas. Tais implicações servem de guia para ações e para a criação de novas experiências, iniciando assim o ciclo.

Segundo Harb, Durrant e Terry (1993), a evolução do estudante na aprendizagem, baseada no ciclo, pode ser auxiliada pela escolha apropriada de atividades de aprendizagem, as quais devem ser distribuídas levando em consideração os diferentes estilos.

Com base nos estudos do sistema 4MAT, algumas considerações são relevantes para que o professor consiga, em seu sistema de ensino, contemplar um número maior de estudantes. São elas:

- Estar ciente de que percorrer o ciclo é natural para o professor, mas não para o aluno;

- É necessário que o professor conduza o estudante ao redor do ciclo;

- Uma forma de conduzi-lo é saber estabelecer perguntas adequadas ao quadrante em que o estudante se encontra; e

- Não adianta fornecer informações sobre um quadrante e fazer pergunta cujas respostas estão em outros quadrantes. Isso causará desmotivação ao estudante.

Para que o professor de engenharia possa ensinar por meio do ciclo, são fornecidas algumas dicas: relacionar o material apresentado ao que foi visto anteriormente (na mesma disciplina ou em outras); procurar equilibrar o volume de informações concretas, conceitos abstratos e métodos práticos; utilizar figuras, gráficos, esboços antes e depois das apresentações verbais; exibir filmes; planejar intervalos breves entre as explicações para que os estudantes possam refletir acerca do que foi ensinado; realizar atividades em grupo; apresentar exercícios que exijam análise e síntese; incentivar soluções criativas; dialogar com os estudantes sobre os estilos de aprendizagem. Vale ressaltar que existem métodos de ensino específicos para cada um dos quatro quadrantes do ciclo, tais como: o questionamento, a exposição, o treinamento e a simulação. 
Os professores de engenharia precisam se conscientizar de que a utilização de diferentes métodos/estratégias de ensino pode representar grandes diferenças nos resultados do aprendizado além de possibilitar um papel ativo do aluno pela proposição de atividades que favoreçam os diferentes estilos de aprendizagem.

\section{Inter-relação entre as bases teóricas e matriz de relacionamentos}

A Figura 4 apresenta a matriz de relacionamentos para a capacitação de professores para o ensino a distância.

A concepção dessa matriz de relacionamentos vem ao encontro da necessidade de capacitar o professor com as habilidades, atitudes e conhecimentos adequados à modalidade do ensino a distância. É necessário que ele se adapte a essa nova realidade e consiga pôr em prática todo o potencial dessa alternativa educacional, visando atender às necessidades e exigências da sociedade atual. É importante fazer com que o professor de engenharia atue de uma maneira diferente da que está acostumado no ensino presencial, pensando nas exigências desse processo de educação em massa. Para que isso ocorra, ele deve estar preparado para criar um sistema de aprendizagem menos formal do que o tradicional, mais flexível e que procure atender a uma quantidade e variedade maior de estudantes, independentemente da localização física e do fator tempo. Para que esse sistema de aprendizagem atenda da melhor maneira a cada tipo de estudante, é preciso construí-lo utilizando tecnologia educacional (que procura aplicar de forma sistemática conhecimentos científicos e tecnológicos), cuja fundamentação está nas áreas da psicologia, teoria de sistemas e teoria das comunicações (Figura 4 - modelo não formal).

Um primeiro passo para a construção de um sistema de aprendizagem menos formal é o estabelecimento de objetivos, sejam eles genéricos ou específicos às atividades instrucionais. Estabelecer objetivos é uma atividade fundamental no processo de planejamento do ensino, por isso a necessidade de se estudar sistemas que auxiliam na identificação e classificação de objetivos. $\mathrm{O}$ sistema de classificação estudado foi a taxonomia proposta por Bloom et al. (1972), apresentada na seção 3.2. A definição dessas classes foi realizada de tal forma que os objetivos categorizáveis em uma classe compreendessem e se baseassem em comportamentos incluídos nas classes precedentes do esquema (Figura 4 - objetivos instrucionais). A especificação dos objetivos é importante para verificar se os resultados esperados de um sistema de aprendizagem ou de uma atividade instrucional ou de um estudante foram alcançados.

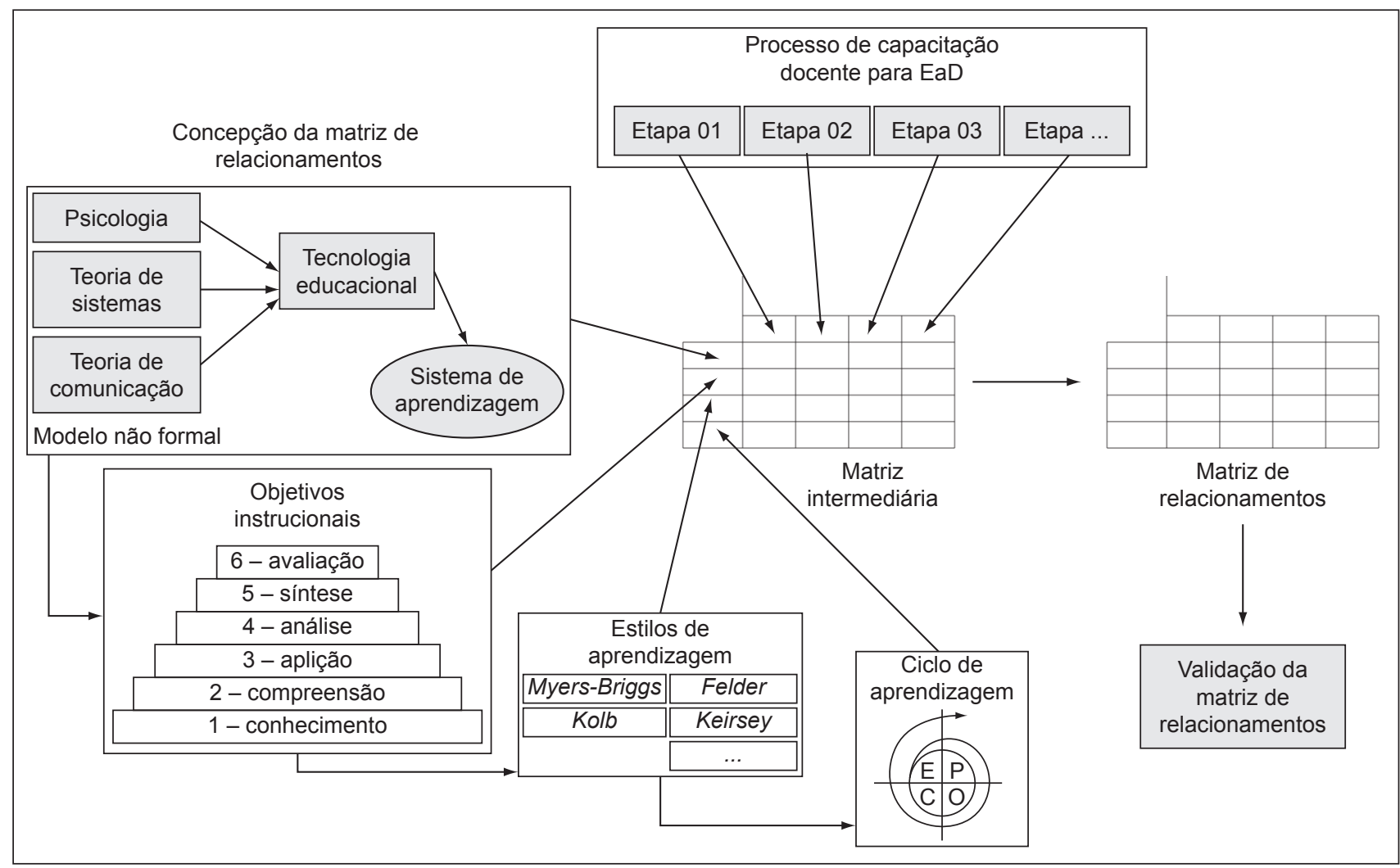

Figura 4. Concepção da matriz de relacionamentos. 
Informações referentes às preferências de aprendizagens dos estudantes podem ser úteis aos professores, contribuindo para que os objetivos estabelecidos possam ser atingidos de uma maneira mais eficiente e eficaz, motivando e tornando a aprendizagem mais agradável. Tais informações podem ser obtidas por meio de modelos, disponíveis na literatura, que ajudam a identificar as características preferenciais de aprendizagem dos estudantes, auxiliando os professores na definição de melhores estratégias de ensino, contribuindo para a maximização da aprendizagem (Figura 4 - Estilos de aprendizagem).

Ensinar para estudantes com modos preferenciais de aprendizagem diferentes passa a ser uma necessidade. Uma possível forma de se tentar abranger os diferentes estilos de aprendizagem é utilizar o conceito de McCarthy (1986) ensinando ao redor do ciclo (vide Seção 3.4). Ensinar ao redor do ciclo possibilita ao professor estabelecer objetivos para cada quadrante, estimulando os diferentes estilos de aprendizagem dos alunos. Estabelecer objetivos às atividades de aprendizagem baseadas nas etapas do ciclo auxilia o professor a conduzir o estudante aos quatro quadrantes (Por quê?) (O quê?) (Como?) (E Se?) (Figura 4 - Ciclo de aprendizagem).

Como se pode observar na Figura 4, a matriz de relacionamentos foi criada a partir de uma matriz intermediária, que tem em um de seus eixos as etapas do processo de capacitação docente para o ensino a distância e no outro o referencial teórico baseado na literatura. A partir dessa delimitação de escopo e estabelecimento da região de fronteira, permeados pelos referenciais teóricos e pelas etapas do processo de capacitação, a tarefa de se especificar as competências a serem desenvolvidas torna-se mais fácil, contribuindo para que o processo de capacitação seja mais bem elaborado, direcionado ou, ainda, adaptado.

\section{5 llustração da matriz de relacionamentos para a capacitação de docentes da engenharia de produção}

Esta seção não tem como objetivo apresentar pressupostos fechados, como modelos prontos e acabados, mas sim promover discussões, exemplos, a fim de elucidar a matriz de relacionamentos. A intenção é ilustrar como seria a utilização da matriz no contexto da engenharia de produção.
A Tabela 1 mostra a intersecção entre os dois eixos da matriz intermediária sinalizando que em determinadas etapas do processo de capacitação docente se deseja desenvolver competências relacionadas a determinados pilares do referencial teórico. Para fins de ilustração considerou-se apenas a etapa de "Material Didático".

Conforme se observa, dentre os quatro pilares do referencial teórico somente em três indicadas na Tabela 1 , são requeridas competências para a etapa de "Material Didático": objetivos instrucionais, estilos de aprendizagem e ciclo de aprendizagem.

A partir desses três referenciais sinalizados deverão ser estabelecidas as competências que um professor de engenharia de produção deverá adquirir pra ser capaz de elaborar material didático para EaD. É importante ressaltar que deve existir uma relação entre o processo de capacitação do professor com o papel que ele exerce dentro de sua área específica de atuação, ou seja, as competências identificadas a serem trabalhadas no processo de capacitação devem contribuir para que o professor desenvolva em seus alunos as competências requeridas ao engenheiro de produção. Isso significa que a maneira de se trabalhar as competências, dentro de um processo de capacitação para $\mathrm{EaD}$, pode ser diferente de uma área/subárea para outra.

Para que as discussões não ficassem muito extensas optou-se por enfocar somente o referencial "Estilos de Aprendizagem". A discussão dos outros dois referenciais sinalizados na Tabela 1 fica para uma oportunidade futura.

Um primeiro aspecto a ser trabalhado no processo de capacitação de um docente de engenharia de produção para $\mathrm{EaD}$ se refere ao conhecimento sobre estilos de aprendizagem. A partir desse conhecimento uma primeira competência pode ser definida: "identificar os estilos de aprendizagem dos alunos". Essa identificação pode ser realizada por meio de instrumentos criados a partir de alguns modelos de estilos de aprendizagem (vide seção 3.3). No site do grupo de pesquisa "Aprende" (www.prod.eesc.usp. br/aprende/) da Escola de Engenharia de São Carlos - USP, departamento de Engenharia de Produção, é possível realizar o teste de estilos baseado nos modelos de Felder e Silverman (1988) e Keirsey e Bates (1984).

Os estudos realizados por Belhot (2005b), a partir de um mapeamento dos estilos de aprendizagem dos alunos

Tabela 1. Matriz intermediária.

\begin{tabular}{cccccc}
\hline Referencial teórico & \multicolumn{4}{c}{ Etapas relacionadas à capacitação de professores para o ensino a distância } \\
\cline { 2 - 6 } (itens da revisão da literatura) & Planejamento & Material didático & Interação & Avaliação & ... \\
\hline Modelo não formal & - & - & - & - & - \\
Objetivos instrucionais & - & $*$ & - & - & - \\
Estilos de aprendizagem & - & $*$ & - & - \\
Ciclo de aprendizagem & - & & - & - \\
\hline
\end{tabular}


de engenharia de produção do $1^{\circ}$ ao $5^{\circ}$ ano, apontam que existe uma tendência dos alunos em serem mais ativos, sensoriais, visuais e globais.

Para fins de ilustração, considere que um professor de engenharia de produção tenha identificado em sua turma alunos cujos estilos são os mesmos apontados por Belhot. Graças à competência "identificar os estilos de aprendizagem dos alunos", determinada a partir do referencial teórico "Estilos de Aprendizagem", é possível direcionar a ação do professor para contemplar esses estilos quando da elaboração do material didático para $\mathrm{EaD}$, o que requer uma nova competência - "proceder de acordo com os estilos identificados". Por exemplo, os professores devem privilegiar atividades participativas ou em grupo (ativos), que trabalhem com problemas práticos ou apliquem conceitos às situações do mundo real (sensoriais), não se restringindo apenas a aulas puramente faladas ou escritas (que atendem os alunos do tipo verbal). Outra estratégia é primeiramente expor com clareza quais são os objetivos da disciplina, sua importância e relacionamentos, a fim de que os alunos do tipo global possam ter seu processo de compreensão acelerado.

Outro aspecto interessante observado por Belhot (2005b) é que os alunos de engenharia de produção são em sua maioria extrovertidos, altamente estruturados e racionais. Para atender esses estilos, os professores devem propor atividades que permitam contato entre os alunos (extrovertidos), as regras devem ser inicialmente estabelecidas de tal maneira a proporcionar um planejamento prévio, uma vez que os alunos estruturados não gostam de surpresas. A dimensão racional sugere que os alunos usam a lógica para tomar suas decisões, são objetivos e preferem ser julgados pelo que fazem e não pelo que são, logo, o professor deve explicar a relevância das atividades a fim de que faça sentido para os alunos.

É sugerido, também, que o professor informe ao aluno quais são seus estilos preferenciais de aprendizagem a fim de que o estudante possa se conhecer melhor. Essa informação pode ser útil para a melhoria do aprendizado uma vez que o aluno pode procurar desenvolver os estilos menos preferenciais e/ou adaptar seu estilo à forma com que lhe é ensinado criando um ambiente de aprendizagem que maximize a satisfação do aprender, proporcionando alto grau de motivação.
Um estudo realizado por Kuri (2004) identifica e caracteriza os estilos de aprendizagem não só dos alunos da engenharia de produção, mas também de outras engenharias de uma universidade pública do interior do Estado de São Paulo. Nesse trabalho, Kuri procura avaliar como o ensino de engenharia pode se beneficiar do conhecimento dos estilos de aprendizagem de seus estudantes, além de sugerir estratégias de ensino e aprendizagem que melhor atendam aos estilos identificados.

Tendo em vista a ilustração discutida nesta seção, a matriz de relacionamentos construída pode ser visualizada da seguinte forma (Tabela 2).

As duas competências indicadas na Tabela 2 são extremamente importantes na educação a distância, especialmente na elaboração do material didático. Considerar os modos de aprendizagem dos estudantes pode significar diminuição da evasão (uma vez que o material didático serve como agente motivador minimizando a ausência do contato presencial entre professor e aluno) e contribuir para uma melhor aprendizagem.

Com relação à competência "proceder de acordo com os estilos identificados" é possível realizar um desmembramento, ou seja, criar outras competências a partir dela, especificamente para atender a cada um dos estilos (essas novas competências podem estar relacionadas, por exemplo, à determinados métodos/técnicas de ensino).

É importante ressaltar que esta seção simplesmente apresentou uma ilustração de como a matriz de relacionamentos pode ser utilizada na engenharia de produção. Esse processo de identificação de competências é contínuo, não termina aqui.

A partir do momento que forem identificadas as competências para cada etapa do processo de capacitação, o próximo passo (desafio) é verificar se e como cada etapa está contribuindo para que sejam atingidas, sendo necessário para isso estabelecer critérios e métricas que possam avaliar se os objetivos estão sendo alcançados e em que grau. De nada adianta definir boas competências se os objetivos, conteúdos e instruções de cada etapa não as considerarem. Um modelo de referência que sistematiza o processo de capacitação docente para $\mathrm{EaD}$ levando em consideração a aquisição de determinadas competências é apresentado em Seno (2007). Nesse trabalho também são

Tabela 2. Matriz de relacionamentos: especificação das competências a partir do referencial "estilos de aprendizagem".

\begin{tabular}{lcrrrr}
\hline \multicolumn{1}{c}{ Competências identificadas } & \multicolumn{3}{c}{ Etapas relacionadas à capacitação de professores para o ensino a distância } \\
\cline { 2 - 5 } & Planejamento & Material didático & Interação & Avaliação & $\ldots$ \\
\hline Identificar estilos de aprendizagem & - & $*$ & - & - \\
Proceder de acordo com os estilos identificados & - & $*$ & - & - \\
XX & - & - & - & - \\
YY & - & - & - & - & - \\
$\ldots$ & - & - & - & - \\
\hline
\end{tabular}


identificadas vinte competências a partir do referencial teórico apresentado.

\section{Considerações finais}

Este artigo apresentou a concepção de uma matriz de relacionamentos como referência para a elaboração de programas customizados de capacitação docente para o ensino a distância pela delimitação de um escopo a partir do qual as competências poderão ser identificadas. Além de fornecer uma visão geral da matriz, foi realizada uma abstração de como ela poderia ser utilizada na engenharia de produção. A concepção dessa matriz baseou-se nos estudos referentes às áreas da educação a distância e formação de competências, além dos quatro pilares adotados como referencial teórico.

As observações citadas em cada um dos pilares podem vir a se tornar competências requeridas para que um professor de engenharia possa trabalhar com a modalidade de ensino a distância ou, ainda, podem contribuir na identificação dessas competências. A identificação das competências que irão compor a matriz é baseada nos temas adotados como fundamentação teórica, isso significa que diferentes competências podem ser identificadas dependendo dos princípios teóricos utilizados. Um referencial teórico pode servir de suporte para a elaboração de várias competências, que por sua vez podem estar presentes em várias etapas do processo de capacitação.

A elaboração da matriz de relacionamentos contribui para determinar e/ou esclarecer o processo de capacitação de professores para o ensino a distância, identificando as particularidades de cada atividade de modo a desenvolver para cada etapa desse processo as competências necessárias, possibilitando maior qualidade no ensino na modalidade a distância.

A especificação de quais competências são necessárias ao professor e em que etapa do processo de capacitação elas devam ser desenvolvidas é de responsabilidade da instituição de ensino e de seu órgão responsável pela educação a distância, mesmo porque o processo de capacitação docente não é o mesmo em todas as instituições. A matriz de relacionamentos aqui apresentada auxilia na identificação das competências a serem trabalhadas no processo de capacitação, principalmente a partir da base teórica utilizada para fundamentá-la. A especificação dos quatro pilares limita o escopo e determina a área de fronteira de onde serão extraídas as competências.

É válido ressaltar que a matriz de relacionamentos, apresentada neste artigo, também pode ser utilizada como referência para a capacitação docente para o modelo tradicional de ensino (presencial), não só das engenharias, mas também de várias outras áreas do conhecimento.

Identificar as competências para cada etapa do processo de capacitação, estabelecer como alcançar tais competências a partir de cada etapa e como medir se as etapas do processo de capacitação estão atingindo as competências estabelecidas são alguns desafios a serem enfrentados.

Parece não haver dúvidas de que desenvolver novas competências e/ou resignificar algumas outras irá proporcionar o sucesso dos professores na educação a distância.

Vale destacar que muitas pesquisas estão sendo realizadas no sentido de contribuir para um melhor ensino de engenharia, principalmente quando o assunto abordado é competência. O problema é que na maioria delas o foco está na identificação e no desenvolvimento de competências voltadas ao aluno, e não ao professor. Quando se fala do professor, a ênfase dada, muitas vezes, está na utilização de tecnologias, o que não é suficiente. Pouco tem se discutido sobre a preparação dos professores de engenharia e muito menos sobre a preparação dos da engenharia de produção, em termos de competência. Se isso é sentido no ensino presencial (formal), no ensino a distância é sentido muito mais. Cabe aqui fazer um alerta para que esses assuntos sejam discutidos e aplicados com mais intensidade, uma vez que o professor é um dos elementos principais no processo de ensino e aprendizagem. 


\title{
Bounding the scope for competence identification for the qualification of professors of engineering for distance education
}

\begin{abstract}
Education has been undergoing a revolutionary period in which hopes contrast to uncertainty making the future uncertain. The concepts of time, space, virtual and reality, and material, have been reviewed to adapt to new ways of teaching. In the last years, Distance Education (DE) has been pointed out as an educational alternative allowing a greater flexibility in the teaching and learning processes and have been useful mainly as support in practically every knowledge area, for instance, engineering. Despite the existence of various methodologies and technologies for distance teaching, it is important to emphasize that its application cannot be carried out the same way traditional educational model is. Trying to prevent this to happen, the qualification instructors is a key point once the professor is a fundamental element in this teaching process. Thus, this paper presents a relationship matrix which helps to identify desirable competences for engineering professors who will work with DE. In this sense, an illustration of the matrix in the production engineering context is presented. Such matrix establishes the boundary in which such competences may be reached thus facilitating its identification. The relationship matrix has been conceptualized based on the correlation of teaching theories and on professor qualification processes.
\end{abstract}

Keywords: Distance education. Professor qualification. Engineering. Competence. Relationship matrix.

\section{Referências bibliográficas}

BAZZO, W. A. Ciência, tecnologia e sociedade: e o contexto da educação tecnológica. Florianópolis/SC: Ed. da UFSC, 1998.

BELHOT, R. V. Reflexões e propostas sobre o "ensinar engenharia" para o século XXI. São Carlos, 1997. Tese (Livre-Docência) Escola de Engenharia de São Carlos, Universidade de São Paulo.

BELHOT, R. V. A didática no ensino de engenharia. In: CONGRESSO BRASILEIRO DE ENSINO DE ENGENHARIA - COBENGE, 32, 2005. Anais... Campina Grande/PB, 2005a

BELHOT, R. V. Benefícios do conhecimento dos estilos de aprendizagem no ensino de engenharia de produção. In: CONGRESSO BRASILEIRO DE ENSINO DE ENGENHARIA COBENGE, 32, 2005. Anais... Campina Grande/PB, 2005b.

BLOOM, B. S. et al. Taxionomia de objetivos educacionais: domínio cognitivo. Tradução de Flávia Maria Sant'Anna. Porto Alegre/RS: Globo, 1972.

CONTRERAS, J. A autonomia de professores. São Paulo: Cortez, 2002.

DIB, C. Z. Especificação operacional de objetivos em ensino e instrução programada. Ciência e Cultura, v. 2, n. 19, 1967.

DIB, C. Z. Tecnologia da educação e sua aplicação à aprendizagem de física. São Paulo: Pioneira, 1974.

FELDER, R. M. Matters of style. ASEE Prism, v. 6, n. 4, p. 18-23, 1996.

FELDER, R. M.; SILVERMAN, L. K. Learning styles and teaching styles in engineering education. Journal of Engineering Education, v. 78, p. 674-681, 1988.

HARB, J. N.; DURRANT S. O.; TERRY R. E. Use of the Kolb learning cycle and the 4MAT system in engineering education. Journal of Engineering Education, v. 82, n. 2, p. 70-77, 1993.

HIDALGA, W. A. Engenheiros professores: uma primeira aproximação de suas concepções sobre os saberes docentes. São Bernardo, SP, 2006. Dissertação (Mestrado) - Programa de Pós-Graduação em Educação, Universidade Metodista de São Paulo.

KEIRSEY, D.; BATES, M. Please understand me. Del Mar. California: Prometheus Nemesis Book Company, 1984.

KOLB, D. A. Experiential learning: experience as the source of learning and development. Englewood Cliffs: Prentice-Hall, 1984.

KURI, N. P. Tipos de personalidade e estilos de aprendizagem: proposições para o ensino de engenharia. São Carlos, SP, 2004. Tese (Doutorado), Programa de Pós-Graduação em Engenharia de Produção, Universidade Federal de São Carlos.

MATOS, L. F. S.; RUDOLF, E. C. A LDB e a formação do engenheiroprofessor. In: CONGRESSO BRASILEIRO DE ENSINO DE ENGENHARIA - COBENGE, 34, 2006. Anais... Passo Fundo/ RS, 2006.

MCCARTHY, B. The 4MAT system: teaching to learning styles with right/left mode techniques. Barrington: Excel, 1986.

MYERS, I. B.; MYERS P. B. Gifts differing, consulting psychologists press. Palo Alto: Calif, 1980.

OLIVEIRA, E. G. Educação à distância na transição paradigmática. Campinas: Papirus, 2003.

REIS, C. A. C. A formação do professor de engenharia. In: SEMINÁRIO NACIONAL DE EDUCAÇÃO PROFISSIONAL E TECNOLÓGICA, 1, 2008. Belo Horizonte/MG: CEFET-MG, 2008. v. 1.

SENO, W. P.; BELHOT, R. V. Educação a distância e a importância da capacitação docente. In: WORLD CONGRESS ON COMPUTER SCIENCE, ENGINEERING AND TECHNOLOGY EDUCATION - WCCSETE`2006, Itanhaém/SP. Proceedings... 2006a

SENO, W. P.; BELHOT, R. V. Criação de uma matriz de competências para a capacitação de professores para o ensino a distância. São Carlos: Programa de Pós-Graduação em Engenharia de 
Produção, Escola de Engenharia de São Carlos, USP, 2006 b. Exame de Qualificação.

SENO, W. P. Capacitação docente para a educação à distância sob a óptica de competências: um modelo de referência. São Carlos, 2007. Tese (Doutorado) - Programa de Pós-Graduação em Engenharia de Produção, Escola de Engenharia de São Carlos, USP.

SILVA, L. P.; CECÍLIO, S. A mudança no modelo de ensino e de formação na engenharia. Educação em Revista, Belo Horizonte/ MG, v. 45, p. 61-80, 2007.

SMITH, K. A.; WALLER A. A. New paradigms for engineering education. In: ANNUAL CONFERENCE - TEACHING AND
LEARNING IN AN ERA OF CHANGE, 27. Proceedings... 1997, v. 3.

STICE, J. Using Kolb’s learning cycle to improve student learning. Journal of Engineering Education, v. 77, p. 291-296, 1987.

STUMP, S. M. D.; ZASNICOFF, L. S. Considerações sobre a formação de engenheiros-professores do curso de mestrado em engenharia elétrica. In: ENCONTRO DE ENSINO DE ENGENHARIA, 5, 1999, Itaipava/RJ. Anais...

TEDESCO, J. C. Educação e novas tecnologias: esperança ou incerteza? Tradução de Claudia Berliner, Silvana Cobucci Leite. São Paulo: Cortez, 2004.

\section{Sobre os autores}

\section{Wesley Peron Seno}

Departamento de Engenharia de Produção - SEP, Escola de Engenharia de São Carlos (EESC), Universidade de São Paulo - USP Avenida Trabalhador São Carlense, 400, Centro, São Carlos, SP - Brasil

e-mail: wesley@fpte.br

\section{Renato Vairo Belhot}

Departamento de Engenharia de Produção - SEP, Escola de Engenharia de São Carlos (EESC), Universidade de São Paulo - USP Avenida Trabalhador São Carlense, 400, Centro, São Carlos, SP - Brasil

e-mail: vairo@sc.usp.br 